\title{
In sacco kinetics disappearance of NDF of small and large particles of the rumen contents in grazing dairy cows
}

\author{
A. Boudon ${ }^{1}$ and J.-L. Peyraud \\ INRA, Agrocampus Rennes, UMR 1080, Milk Production \\ F-35590 St-Gilles, France
}

\begin{abstract}
In sacco degradation curves of NDF from small (SP) and large particles (LP) of rumen contents, collected in dairy cows before or after grazing, were compared. LP and SP were defined as ruminal particles retained, or passing a $1 \mathrm{~mm}$-pore-sieve, respectively. Degradation curves were fitted with a first order kinetics model. SP, compared to LP, contained a lower proportion of digestible NDF. Fractional degradation rates of NDF were lower for SP than for LP after the meal, and were not different between SP and LP before the meal. These results questions about representations of SP and LP in the rumen models.
\end{abstract}

KEY WORDS: rumen digestion, modelling, particle size, degradation rate

\section{INTRODUCTION}

In rumen mechanistic models, dividing ruminal contents into large (LP) and small particles (SP) is usually considered necessary to account for a selective retention of LP in the rumen (Baldwin et al., 1987; Sauvant et al., 1996; CollaoSaenz et al., 2005). The consideration of LP and SP pools could be of particular importance in non steady-state rumen models designed to predict daily variation of intake and feeding behaviour of ruminants. The objective of this paper was to improve the description of fibre of ruminal LP and SP pools of grazing dairy cows and to specifically measure their in sacco fractional degradation rate.

\footnotetext{
${ }^{1}$ Corresponding author: e-mail: Anne.Boudon@rennes.inra.fr
} 


\section{MATERIAL AND METHODS}

Samples of ruminal contents were collected from 4 grazing dairy cows, fitted with a rumen cannula, at $09.30 \mathrm{~h}$ after milking and before the entry on the daily pasture, and at $14.00 \mathrm{~h}$ after $4 \mathrm{~h}$ grazing. The cows were strip grazed a 20 -dayregrowth perennial ryegrass, at the beginning of May. The herbage allowance was $15 \mathrm{~kg}$ DM above $5 \mathrm{~cm}$ per cow per day. The cows were multiparous PrimHolstein with an average stage of lactation of $169( \pm 29.2)$ days in milk, a daily milk production of $25.8 \pm 3.14 \mathrm{~kg} / \mathrm{d}$ and a liveweight of $662( \pm 29.5) \mathrm{kg}$. Procedure relating to care and use of animals for the experiment were approved by an animal care committee of the French Ministry of Agriculture (Decree-law 2001-464, May 29, 2001).

For each ruminal sampling, the whole reticulo-rumen digesta were manually emptied and weighed at 09.30 and $14.00 \mathrm{~h}$. For each ruminal sampling time and for each cow, a 5\% weight sample of total rumen contents was taken and the remainder was returned to the animal. A part was used for DM determination $\left(72 \mathrm{~h}, 80^{\circ} \mathrm{C}\right)$ before subsequent analyses of fibre and $\mathrm{N}$, the reminder was frozen $\left(-20^{\circ} \mathrm{C}\right)$ for wet-sieving. The fibre were analysed using the method of Van Soest and Wine (1967) and N was determined by the Dumas method on a Leco apparatus (Leco, St. Joseph, MI49085, USA).

SP and LP were obtained by wet sieving of the reticulo-ruminal digesta. The pore size of the sieve used for separation of SP and LP was $1 \mathrm{~mm}$. The pore size of threshold sieve was determined by wet-sieving of faeces before the experiment. For this, an average faeces sample was collected for each cow at the end of the day, on the grazed plot. Particle size distribution of faeces was analysed by wet sieving using an oscillating sieve shaker (Analysette 3, Fritsch). Sieve pore sizes were $4,2,1,0.5,0.25,0.125$ and $0.0625 \mathrm{~mm}$. The selected critical pore size was that of the first sieve, from bottom to top, that retained less than $15 \%$ of the total faeces particulate dry matter.

LP and SP of rumen contents were separated using a simplified procedure of wet-sieving. Subsamples of $100 \mathrm{~g}$ (fresh weight) of ruminal digesta were thawed and stirred into $400 \mathrm{ml}$ water before to be poured on the top sieve on the sieve shaker. Sieve pore sizes were $8,1,0.25$ and $0.0625 \mathrm{~mm}$. The number of sieve was limited to shorten the process. Sieves 8 and $0.25 \mathrm{~mm}$ were used to prevent matting phenomena in each sieve. The sieving was carried out 2 cycles of 5 min with an amplitude of 80 and a water flow of $1.3 \mathrm{l} / \mathrm{min}$. Particles retained on the 8 and $1 \mathrm{~mm}$ sieves were added in the sample of LP and particles retained on the 0.25 and $0.0625 \mathrm{~mm}$ sieves were added in the sample of SP (1 sample of LP and SP per cow and per sampling time). Samples were kept at $-20^{\circ} \mathrm{C}$ before being filtered through a buchner funnel, covered with Whatman filter (Cat. No. 1441 150), and plugged on an empty vacuum flask. 
An aliquot of LP and SP was oven-dried for DM determination and subsequently analysed for fibre (NDF, ADF, ADL) and $\mathrm{N}$ contents. To determine the in sacco kinetics of NDF disappearance, 24 nylon bags were filled for each rumen sampling time, cow and particle size. The fresh weight of particle per nylon bags was calculated to be equivalent to $1.3 \mathrm{~g} \mathrm{DM}$. The incubation times were 2 ( 2 bags), 4 (3 bags), 8 (4 bags), 24 ( 5 bags) and $48 \mathrm{~h}$ (10 bags). The number of bags incubated increased with incubation times to ensure that enough material would be collected after incubation for analyses. The size of the bags was $115 \times 70 \mathrm{~mm}$ and the pore size of the nylon was $50 \mu \mathrm{m}$. All the bags sampled from a given cow in May were incubated in the same cow at mid June, which means that 96 bags were incubated per cow. Incubation were carried during 6 days, according to 3 successive series of 2 day incubations. During incubation, the cows were strip grazed perennial ryegrass. After incubation, bags were washed in tap water, ovendried $\left(48 \mathrm{~h}, 80^{\circ} \mathrm{C}\right)$, gathered per incubation time, cow, rumen sampling time and particle size before to be analysed for NDF contents.

Data were analysed by analyses of variance using the MIXED procedure of SAS (1999), the animal being included as a random effect. For data related to reticulorumen contents, only effect of sampling time was included in the model. For data related to LP and SP, effects included in the model were ruminal sampling time (1df), particle size (1df) and the interaction between both. For dynamics of NDF disappearance from the bags, time and its interaction with the other effects of the model were included and the statement REPEATED was used with a covariance matrix designed according an autoregressive model of order 1 . All the in sacco disappearance curves were fitted to a first order kinetics models, without the lag phase first, and then with the lag phase, using the NLIN procedure of SAS:

$$
D=P o t \times(1-\exp (-k d \times(t-L))
$$

where: $D$ is the proportion disappeared from the bags at the time $t$, Pot is the fraction that is potentially degraded over time, $k d$ is the fractional degradation rate of Pot and $L$ the discrete lag-time. The fraction that instantaneously disappears from the bag was voluntary omitted assuming it had been previously washed during wet-sieving.

\section{RESULTS}

The perennial ryegrass offered to the cows during ruminal sampling was vegetative and had a dry matter (DM) content of $13.0 \%$, and NDF, ADF and ADL contents of 54.1, 23.4 and $1.76 \%$ DM, respectively. Before grazing, the weight of the reticulo-rumen contents was on average $71.4 \mathrm{~kg}$ (fresh weight) and $7.24 \mathrm{~kg}$ 
(dry weight). Weights of ruminal contents increased by $23.9 \mathrm{~kg}$ for fresh weight $(\mathrm{P}<0.01)$ and by $2.58 \mathrm{~kg}$ for dry weight $(\mathrm{P}<0.001)$. The proportion of fibre in the ruminal contents was lower after grazing than before. More specifically, the ADL contents was almost 2.9 points lower after grazing than before $(\mathrm{P}<0.001)$. The LP represented $64 \%( \pm 2.2)$ of the particulate DM and this value tended to be lower after than before grazing $(\mathrm{P}<0.10)$.

The NDF and ADF contents of LP (Table 1) were higher compared to SP $(\mathrm{P}<0.001)$ but the ADL content of LP was 2.8 points lower $(\mathrm{P}<0.001)$. For LP, the NDF content was lower after than before grazing whereas it did not vary significantly according to the sampling time for SP (interaction; $\mathrm{P}<0.001$ ).

Table 1. Chemical composition and kinetics parameters of in sacco disappearance of large and small particles of reticulo-rumen contents at 09.30 and $14.00 \mathrm{~h}$

\begin{tabular}{|c|c|c|c|c|c|c|c|}
\hline & \multicolumn{4}{|c|}{ Particle sizes and sampling times } & \multirow{3}{*}{ SEM } & \multicolumn{2}{|c|}{ P-value ${ }^{1}$} \\
\hline & \multicolumn{2}{|c|}{ LP } & \multicolumn{2}{|c|}{$\mathrm{SP}$} & & \multirow{2}{*}{ size } & \multirow{2}{*}{$\begin{array}{l}\text { size } \times \\
\text { time }\end{array}$} \\
\hline & 09.30 & 14.00 & 09.30 & 14.00 & & & \\
\hline \multicolumn{8}{|l|}{$\mathrm{g} / 100 \mathrm{~g} \mathrm{DM}$} \\
\hline NDF & 80.7 & 74.8 & 71.3 & 69.5 & 0.74 & $* * *$ & $* *$ \\
\hline $\mathrm{ADF}$ & 41.3 & 39.8 & 34.6 & 34.2 & 0.69 & $* * *$ & NS \\
\hline $\mathrm{ADL}$ & 6.98 & 6.32 & 9.89 & 9.10 & 0.579 & $* * *$ & NS \\
\hline $\mathrm{DNDF}^{2,3}, \mathrm{~g} / 100 \mathrm{~g} \mathrm{NDF}, \mathrm{A}$ & 40.8 & 59.2 & 28.3 & 37.2 & 6.18 & $*$ & NS \\
\hline Digestion rate ${ }^{3}, \% / h, k d$ & 4.7 & 9.1 & 6.0 & 4.7 & 1.75 & NS & $*$ \\
\hline Lag time ${ }^{3}, \mathrm{~h} 1$ & 0.00 & 0.28 & 2.23 & 0.70 & 0.638 & $\dagger$ & NS \\
\hline
\end{tabular}
in sacco disappearance curves with first order kinetics model

The proportion of NDF disappeared from nylon bags during incubation (Figure 1) were systematically higher for LP than for SP, and for rumen contents collected after than before grazing, the difference being significant for incubation higher than $8 \mathrm{~h}(\mathrm{P}<0.001)$. For incubation time higher than $8 \mathrm{~h}$, the proportion of NDF disappeared from LP was largely higher for rumen content sampled after grazing than for rumen content sampled before grazing whereas the sampling time did not affect the proportion of NDF disappeared from SP (interaction; $\mathrm{P}<0.001$ ).

All the disappearance curves could be fitted to the first order kinetics model. Discrete-lag parameter had to be included for some curves to obtain convergence. When curves could be fitted with and without lag phase, the model giving the best residual mean square with parameters within acceptable bounds was kept. The proportion of degradable NDF (Table 1) was higher for LP compared to SP $(\mathrm{P}<0.001)$, and after grazing compared to before grazing $(\mathrm{P}<0.001)$. For $\mathrm{LP}$, the rate of NDF degradation was higher after than before grazing whereas it was not significantly affected for SP (interaction; $\mathrm{P}<0.05$ ). The lag-time was shorter for LP compared to SP. 


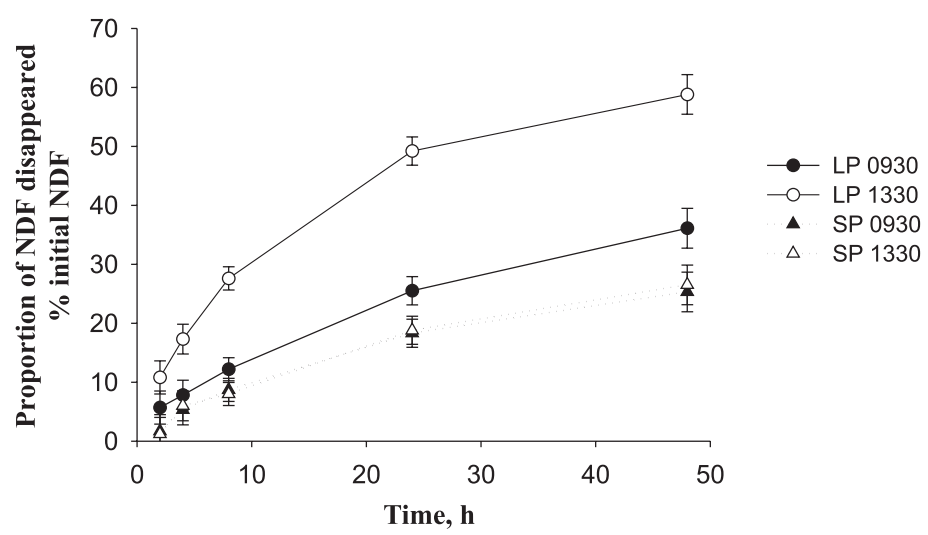

Figure 1. Disappearance curves of NDF from nylon bags for large (LP) and small particles (SP) of rumen contents collected before grazing $(09.30 \mathrm{~h})$ or after $4 \mathrm{~h}$ grazing $(14.00 \mathrm{~h})$

\section{DISCUSSION}

The fractional degradation rate of NDF was not systematically lower for SP compared to LP. This suggests that the higher in sacco digestion rate of DM or NDF reported when the particles size of the feed decreased (Michalet-Doreau and Ould-Bah, 1992) is not applicable to SP, compared to LP, when considering the degradation rate of these fractions isolated from the rumen contents. Moreover, the content of potentially digestible NDF was far lower for SP than for LP. The reason likely was that SP should have spent a longer time in the rumen to reach the smallest size. This is in good agreement with the lower $k d$ and content of digestible NDF in LP before grazing than immediately after grazing.

In the present experiment, the fractional degradation rate of freshly ingested particles, i.e. of LP at $14.00 \mathrm{~h}$, was twice higher compared to LP at $09.30 \mathrm{~h}$ or SP at both sampling times. The difference in the rate of degradation of LP between 9.30 and 14.00 raises the question of the relevance of considering a first-order digestion rate of potentially digestible NDF (Pot). The degradation rates of NDF observed in this experiment were in the range of those generally observed on that kind of forage (Illius and Gordon, 1991).

Therefore it may not be relevant to consider in ruminal models a higher rate of degradation for fibre contained in the SP pools than for those contained in the LP pools. In the model of Sauvant et al. (1996), the degradation rate of digestible NDF in LP was 0.8 times that in SP and in the model of Baldwin et al. (1987) and Collao-Saenz et al. (2005), the degradation rate of LP was considered negligible compared to that of SP. Sauvant et al. (1996) calculated that a variation of $20 \%$ 
of the ratio between degradation rates of SP and LP had a limited impact on dry matter intake prediction in their model. However, the impact of considering a degradation rate of LP 1.5 times that of SP on parameters related to rumen contents remained to be assessed in the cited models.

The lower proportion of digestible NDF in SP could be hardly predicted by the chemical fraction of fibre, except by their higher content of ADL. This underlies the relevance of considering pools of digestible NDF rather than pools of NDF in models aimed to understand the ruminal fate of fibre.

\section{CONCLUSIONS}

Ruminal small particles had a lower proportion of digestible NDF and could have a lower in sacco NDF fractional degradation rate than larger ones, at least on cows fed fresh grass. These results point out that the relative kinetics of digestion for small and large particles of ruminal contents in rumen mechanistic models could not be extrapolated from kinetics of digestion of small and large particles stemming from a same feed in studies where feed particle size was modified by milling.

\section{REFERENCES}

Baldwin R.L., Thornley J.H.M., Beever D.E., 1987. Metabolism of the lactating cow II. Digestive element of a mechanistic model. J. Dairy Res. 54, 107-131

Collao-Saenz E.A., Dijkstra J., Paiva P.C., Bannink A., Arcuri P.B., Teixeira J.C., Perez J.R.O., David F.M., 2005. Simulation model for particle dynamics in rumen of cattle fed sugarcane diet. Sci. Agr. 62, 102-110

Illius A.W., Gordon I.J., 1991. Prediction of intake and digestion in ruminants by a model of rumen kinetics integrating animal size and plant characteristics. J. Agr. Sci. 116, 145-157

Michalet-Doreau B., Ould-Bah M.Y., 1992. In vitro and in sacco methods for the estimation of dietary nitrogen degradability in the rumen: a review. Anim. Feed Sci. Tech. 40, 57-86

Sauvant D., Baumont R., Faverdin P., 1996. Development of a mechanistic model of intake and chewing activities of sheep. J. Anim. Sci. 74, 2785-2802

SAS, 1999. SAS OnlineDoc Version 8. SAS Inc. Cary, NC

Van Soest P.J., Wine R.H., 1967. Use of detergents in the analyses of fibrous feeds. Part IV. Determination of plant cell wall constituents. J. Assn. Off. Anal. Chem. 50, 50-55 